\title{
Enhancement of Aqueous Solubility, Dissolution Profile, and Oral Bioavailability of Pentoxifylline by Microsponges
}

Anil Raosaheb Pawar ${ }^{1, *}$ Nikhil Arun Shete ${ }^{1} \quad$ Priyanka Vitthal Jadhav ${ }^{1}$ Vinayak Kashinath Deshmukh ${ }^{1}$ Jaswandi Sameer Mehetre ${ }^{2}$

${ }^{1}$ Department of Pharmaceutics, Mula Education Society's College of Pharmacy, Savitribai Phule Pune University, Sonai, Newasa, Ahmednagar, Maharashtra, India

${ }^{2}$ Department of Pharmacy, School of Pharmacy, ITM (SLS) Baroda University, Vadodara, Gujarat, India

Address for correspondence Anil Raosaheb Pawar, MPharm, PhD, MES's College of Pharmacy, Sonai, Rahuri-Sonai Road, Newasa, Ahmednagar 414105, Maharashtra, India

Pharmaceut Fronts 2021;3:e200-e207.
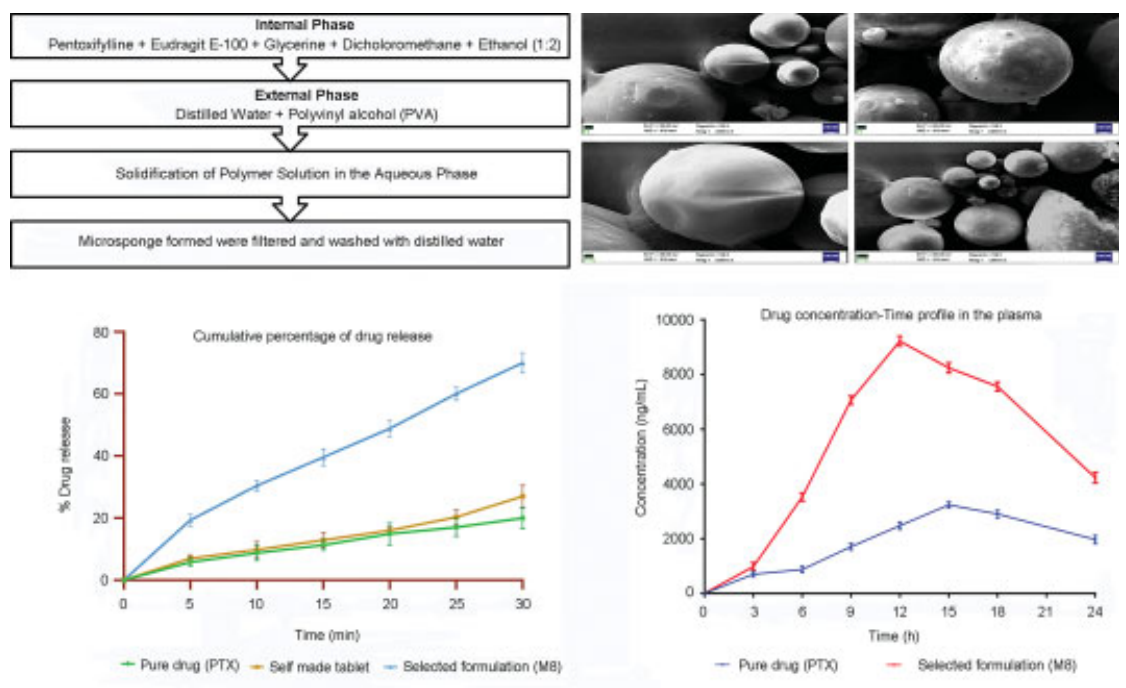
Abstract
Keywords
- microsponges
- pentoxifylline
- quasi-emulsion solvent diffusion method
- aqueous solubility
- dissolution profile
- drug release
- oral bioavailability

Microsponge, a novel drug delivery system, is designed to deliver a pharmaceutically active ingredient efficiently at the minimum dose. Microsponge plays an important role in enhancing drug stability, reducing side effects, and modifying drug release profiles. It is mostly used for transdermal delivery. Recent studies also explored their use for oral administration. This study aimed to explore the potential use of the microsponge technique in improving the aqueous solubility and dissolution profile of pentoxifylline (PTX). In this study, microsponges were prepared by a quasi-emulsion solvent diffusion method by varying concentrations of carriers. Nine different ratios of the PTX:Eudragit E-100 with varying amounts of dichloromethane were used. All formulated microsponges were evaluated for \%production yield, compatibility of drug excipient, received

July 13, 2021

accepted

October 22, 2021
DOI https://doi.org/ $10.1055 / \mathrm{s}-0041-1740242$. ISSN 2628-5088.
(C) 2021. The Author(s).

This is an open access article published by Thieme under the terms of the Creative Commons Attribution License, permitting unrestricted use, distribution, and reproduction so long as the original work is properly cited. (https://creativecommons.org/licenses/by/4.0/)

Georg Thieme Verlag KG, Rüdigerstraße 14, 70469 Stuttgart, Germany 
encapsulation efficiency, in vitro drug release, and in vivo bioavailability, as well as recorded by scanning electron microscopy (SEM) and differential scanning calorimetry (DSC). Our data suggested that the aqueous solubility of PTX microsponges was four times greater than that of pure drug. The in vitro drug release of selected microsponges (M8) was found to be $70 \%$; furthermore, the in vivo study suggested that the selected formulation significantly enhanced drug concentration in the plasma $(9,219 \mathrm{ng} / \mathrm{mL}$ in 12 hours $)$ in comparison to pure drug PTX $(2,476 \mathrm{ng} / \mathrm{mL}$ in 12 hours $)$. SEM showed that the prepared microsponges were spherical with porous nature. Fourier-transform infrared spectroscopy and DSC studies confirmed an absence of incompatibility among drugs and selected excipients. The $\mathrm{pH}$ of the selected gel was found to be 6.8 , which was compatible with those of skin and oral formulations also. All above data suggested a highly successful and beneficial use of the microsponge technique in enhancing aqueous solubility, dissolution profile, and oral bioavailability of PTX. Microspongebased delivery of PTX may represent an alternative strategy to improve the bioavailability of the drug.

\section{Introduction}

Microsponge is a novel class of hyper-cross-linked-polymerbased colloidal structures, which represents an innovative method to control release and target specific drug delivery in recent years. ${ }^{1,2}$ Microsponges are actually porous, spongy, and spherical in shape, and therapeutic moiety can be released from the pores of microsponge in a sustained manner. These are tiny sponge-like spherical particles that consist of myriad of interconnecting voids within a noncollapsible structure with a large porous surface. ${ }^{3}$ The size of these microsponges is varied, usually from 5 to $300 \mu \mathrm{m}$ in diameter. The transdermal delivery system (TDS), using the skin as the portal of entry of active drug, has improved the efficacy and safety of many drugs that may be better administered through dermal application. Unfortunately, TDS is not efficient for delivery of therapeutic moiety whose final target is the skin itself. Controlled release of drugs onto the epidermis ensures that the drug remains primarily localized and does not enter the systemic circulation in significant amounts. Some conventional delivery systems, such as ointments and creams, are inefficient and require high concentrations of active agents for effective therapy, resulting in irritation and allergic reactions in significant numbers of users. Thus, it is necessary to maximize the time that the active ingredient stays either on the skin surface or within the epidermis, while minimize its transdermal penetration into the systemic circulation. The microsponge delivery system fulfills these requirements for Biopharmaceutical Classification System (BCS) class II drugs with low solubility and high permeability. ${ }^{4}$ The size of pore diameter is even smaller than that of bacteria, ranging from 0.007 to $0.2 \mu \mathrm{m}$, which is beneficial for avoiding bacterial contamination of the materials entrapped in the microsponge, and maintaining long-term stability and cost-effectiveness of treatment.

Pentoxifylline (PTX), chemically named 3,7-dimethyl-1(5-oxohexyl)-3,7-dihydro-1H-purine-2,6-dione or 1-(5-oxohexyl)-3,7-dimethylxanthine, is a BCS class II drug. It is a methyl-xanthine derivative, and used as a hemorrheologic agent for the therapy of peripheral artery disease. Due to the slow dissolution rate of PTX, the oral administration of the drug has a bioavailability of only 20 to $30 \%$ that needs to be enhanced. It is well known that microsponges are designed to efficiently deliver a pharmaceutical active ingredient in the minimum dose while enhancing stability, reducing side effects, and improving drug release. In this study, we prepared polymer-based PTX microsponges using a quasi-emulsion solvent diffusion method. PTX microsponges were identified with better aqueous solubility and dissolution rate. In addition to using as a transdermal delivery, microsponges also play a role in oral administration. Therefore, a standard oral dissolution study was further performed to determine the drug release profile. Our data also suggested an improved oral bioavailability of this drug from microsponges.

\section{Materials and Methods}

PTX was received as a gift sample from Shreya Life Science, Aurangabad, Maharashtra, India. Eudragit E-100, dichloromethane (DCM), glycerine, ethanol, and PEG 400 were purchased from Loba Chemie Pvt. Ltd., Mumbai, India. Polyvinyl alcohol (PVA), disodium hydrogen phosphate, and potassium dihydrogen phosphate were obtained from SD Fine Chem Ltd., Mumbai, India. All other chemicals were used of analytical grades.

\section{Preparation of Microsponge}

Eudragit E-100-based PTX-loaded microsponges were prepared by the quasi-emulsion solvent diffusion method. The internal phase consists of Eudragit E-100 dissolved in a mixture of DCM and ethanol (DCM:ethanol=1:1). This was followed by addition of PTX under ultrasonication with $5 \mathrm{~mL}$ glycerin. The surfactant PVA $(60 \mathrm{mg}$ ) was weighed accurately and dissolved in $100 \mathrm{~mL}$ of distilled water at $60^{\circ} \mathrm{C}$. The surfactant mixture was allowed to cool down to room 
Table 1 Composition of PTX microsponges

\begin{tabular}{|l|l|l|l|l|l|l|l|l|l|}
\hline $\begin{array}{l}\text { Speed } \\
(\mathbf{r p m})\end{array}$ & Ratio & $\begin{array}{l}\text { PTX } \\
(\mathbf{m g})\end{array}$ & $\begin{array}{l}\text { Eudragit } \\
(\mathbf{m g})\end{array}$ & $\begin{array}{l}\text { Glycerin } \\
(\% \mathbf{w} / \mathbf{v})\end{array}$ & $\begin{array}{l}\text { DCM } \\
(\mathbf{m L})\end{array}$ & $\begin{array}{l}\text { Ethanol } \\
(\mathbf{m L})\end{array}$ & $\begin{array}{l}\text { PVA } \\
(\mathbf{m g})\end{array}$ & $\begin{array}{l}\text { Water } \\
(\mathbf{m L})\end{array}$ & $\begin{array}{l}\text { Formulation } \\
\text { code }\end{array}$ \\
\hline \multirow{5}{*}{500} & $1: 1$ & 100 & 200 & 5 & 2.5 & 2.5 & 0.5 & 50 & $\mathrm{M} 1$ \\
\cline { 2 - 10 } & $1: 2$ & 100 & 300 & 5 & 2.5 & 2.5 & 0.75 & 50 & $\mathrm{M} 2$ \\
\cline { 2 - 10 } & $1: 3$ & 100 & 400 & 5 & 2.5 & 2.5 & 1 & 50 & $\mathrm{M} 3$ \\
\hline 600 & $1: 4$ & 100 & 300 & 5 & 5 & 5 & 0.5 & 70 & $\mathrm{M} 4$ \\
\cline { 2 - 9 } & $1: 5$ & 100 & 400 & 5 & 5 & 5 & 0.75 & 70 & $\mathrm{M} 5$ \\
\cline { 2 - 9 } & $1: 6$ & 100 & 500 & 5 & 5 & 5 & 1 & 70 & $\mathrm{M} 6$ \\
\hline 700 & $1: 7$ & 100 & 750 & 5 & 5 & 5 & 0.5 & 100 & $\mathrm{M} 7$ \\
\cline { 2 - 9 } & $1: 8$ & 100 & 800 & 5 & 5 & 5 & 0.75 & 100 & $\mathrm{M} 8$ \\
\cline { 2 - 9 } & $1: 9$ & 100 & 850 & 5 & 5 & 5 & 1 & 100 & $\mathrm{M} 9$ \\
\hline
\end{tabular}

Abbreviations: DCM, dichloromethane; PVA, polyvinyl alcohol.

temperature. The internal phase containing PTX and Eudragit E-100 polymer was added dropwise at different stirring rates. After 2 hours of stirring, microsponges were formed due to the removal of solvent from the system by evaporation. The microsponges were washed three times with distilled water, filtered, and dried overnight at room temperature. $^{5}$ The compositions of PTX microsponge are given in -Table 1.

Solubility of Drug and Microsponge in Distilled Water The solubility of the pure drug and drug-loaded microsponges was determined by adding their excess amount to a specified quantity of distilled water in a $10 \mathrm{~mL}$ vial. This dispersion system was stirred by magnetic stirrer for 24 hours at room temperature. Following filtration, the solubility of the pure drug and drug-loaded microsponges was determined by a UV spectrophotometer (V-630, JASCO Corporation, Japan) after dilution with methanol at $277 \mathrm{~nm} .{ }^{6}$

\section{Production Yield}

The production yield of the microsponges was determined by calculating the initial weight and the final weight of the formulation obtained. ${ }^{7}$ The production yield was calculated in triplicate following Eq. (1):

Percentage yield $=\frac{\text { Practical yield }}{\text { Theoretical yield }} \times 100 \%$

\section{Loading/Encapsulation Efficiency}

A sample of dried drug-loaded microsponges $(10 \mathrm{mg})$ in a mortar and pestle was dissolved in a mixture of methanol and distilled water (methanol:distilled water $=40: 60$ ). Then, the solution was added into a $100 \mathrm{~mL}$ volumetric flask to make up the volume. The solution was filtered through Whatman filter paper. The drug content was determined by a UV spectrophotometer at $277 \mathrm{~nm} .^{8}$ The loading efficiency (\%) of the microsponges was calculated following Eq. (2):

Loading efficiency $=\frac{\text { Actual drug in microsponges }}{\text { Theoretical drug concentration }} \times 100 \%$

\section{Appearance}

The prepared microsponge gels containing PTX were evaluated visually for their color, homogeneity, and consistency according to a reported study. ${ }^{9}$

\section{Measurement of pH}

The $\mathrm{pH}$ of the developed microsponges was determined using a digital $\mathrm{pH}$ meter. ${ }^{10}$

\section{FTIR Spectral Analysis}

The structure and purity of the particular compound were characterized by infrared spectroscopy. Fourier-transform infrared (FTIR) spectroscopy was done using $\mathrm{KBr}$ pellets. The scanning ranged from 4,000 to $400 \mathrm{~cm}^{-1}$ and the resolution was $1 \mathrm{~cm}^{-1}$. $^{11}$

\section{Scanning Electron Microscopy}

The morphology of the microsponge was observed by a scanning electron microscope (SEM) operating at $10 \mathrm{kV}$. The microsponge gel was kept on the sample holder, and the SEM photograph was recorded using a SEM (JEOL-JSM 6390 , England) under vacuum at room temperature. ${ }^{12}$

\section{Differential Scanning Calorimetry}

Thermogram was obtained by using a differential scanning calorimetry (DSC) instrument (PerkinElmer 4000) equipped with an intercooler. Indium standard was used to calibrate the DSC temperature and enthalpy scale. The microsponges were hermetically kept in the aluminum pan and heated at a constant rate of $10^{\circ} \mathrm{C} / \mathrm{min}$ from 30 to $300^{\circ} \mathrm{C}$ under a nitrogen atmosphere with a flow rate of $20 \mathrm{~mL} / \mathrm{min}^{13}$

\section{In Vitro Dissolution Study}

Dissolution rates for the prepared microsponges were calculated using the USP paddle method at $50 \mathrm{rpm}$ with a medium of phosphate buffer $(\mathrm{pH} 6.8,900 \mathrm{~mL})$ at $37 \pm 0.5^{\circ} \mathrm{C}$. The samples were collected at specified time intervals $(5,10$, $15,20,25$, and 30 minutes), filtered through Whatman filter paper, and assayed spectrophotometrically at $277 \mathrm{~nm}$. After each sample, the same volume of the fresh medium, 
prewarmed at $37^{\circ} \mathrm{C}$, was replaced with the dissolution media to maintain a constant volume throughout the test. ${ }^{14}$

\section{In Vivo Bioavailability Study (Pharmacokinetic Parameter)}

The in vivo studies were performed to compare the plasma profile of the selected formulation (M8) and the pure drug PTX to evaluate whether the enhanced bioavailability was obtained with the preparation of microsponges. New Zealand White male rabbits (weighed 900-1,500 g; Faculty of Pharmacy, MESCOP, Sonai, Maharashtra, India) were randomly divided into two groups (control and test groups) with $n=6$ in each group. The research protocol of the animal experimentation was approved by the Institutional Animal Ethics Committee, MESCOP, Sonai, Maharashtra, India, and animal handling was performed according to Good Laboratory Practices.

Briefly, the animals were housed in polypropylene cages with free access to standard laboratory diet and water. The animals were fasted for 24 hours before starting the experiment but allowed free access to water. M8 and the drug (PTX) were dissolved separately in $1 \mathrm{~mL}$ of gum acacia solution $(2 \% \mathrm{w} / \mathrm{v})$, and the rabbits in each group were orally given the solution at a dose of $2 \mathrm{mg} / \mathrm{kg}$. At predetermined time intervals, the rabbits were anesthetized with ether. Blood samples (1-1.5 mL) from the ear vein were collected in microcentrifuge tubes, and rinsed with EDTA. Then a small quantity $(4-8 \mathrm{mg})$ of powdered EDTA was added. The collected blood was properly mixed with the anticoagulant by shaking and centrifuged at $4,000 \mathrm{rpm}$ for 20 minutes. The plasma was separated and stored at $-20^{\circ} \mathrm{C}$ for further high-performance liquid chromatography (HPLC) analysis.

For the UV-HPLC method, the analytical column was reverse-phased, $300 \times 3.9 \mathrm{~mm}$ I.D., RP-18 $\mu \mathrm{m}$ Hyperbond (Hypersil). The detection wavelength was $273 \mathrm{~nm}$. The mobile phase was a mixture of methanol:water (58:42, $\mathrm{v} / \mathrm{v}$ ) and the flow rate was $1 \mathrm{~mL} / \mathrm{min}$.

The pharmacokinetic parameters such as area under the curve (AUC), maximum plasma concentration $\left(C_{\max }\right), t_{\max }$, $[\mathrm{AUC}]_{0-t}$, and $[\mathrm{AUC}]_{0-\infty}$ were calculated from plasma profile curves. All pharmacokinetic parameters were calculated individually for each subject. The area under concentration time curve was calculated according to the log trapezoidal method.

\section{Results and Discussion}

\section{Evaluation of PTX Microsponges}

The prepared microsponges were homogeneous, clear, and spongy. The interactions if persist between the drug and polymer were further determined to find out which properties of the polymer make them an efficient material for increasing solubility and thereby bioavailability. Microsponges of PTX with Eudragit E100 were characterized and assessed by physical appearance, production yield and loading efficiency, solubility, pH, FTIR, DSC, SEM, in vitro drug release, in vivo bioavailability, etc.

\section{Solubility Determination}

The data obtained from solubility studies showed four times better solubility for PTX-loaded microsponges (283.65 $\mathrm{mg} / \mathrm{mL})$ than that of pure PTX $(75 \mathrm{mg} / \mathrm{mL})$.

\section{Production Yield and Loading Efficiency}

The production yield, drug content, and loading efficiency of all formulations are given in - Table 2. Our data suggested that the microsponge was associated with enhanced drug loading capacity, and reduced drug loss during and also after its preparation. The maximum loading/encapsulation efficiency was found for the prepared microsponges M8 and M9. The stirring rate ranged between 500 and $700 \mathrm{rpm}$. The dispersion of the drug and polymer into the aqueous phase was dependent on the agitation speed. As the speed was increased, the size of microsponges would be reduced, and spherical and uniformed microsponges were obtained. Higher stirring rates increased the production yield and loading efficiency. Possibly, at higher stirring rates, the polymer did not adhere to the paddle due to the turbulence created within the external phase, and hence the production yield and loading efficiency were increased.

The formulation M1 showed the lowest loading/encapsulation efficiency (35.83\%) as well as formulation M9 showed the highest loading encapsulation efficiency $(97.82 \%)$, yet, with low production yield $(75.78 \%)$ and practical yield $(720 \mathrm{mg})$. However, the formulation M8 showed optimum loading/encapsulation efficiency (95.41\%), and good practical $(756 \mathrm{mg}$ ) and production yield (84\%). Hence, formulation M8 was considered for further studies.

\section{Measurement of $\mathrm{pH}$}

The $\mathrm{pH}$ values of all prepared formulations ranged from 6.2 to 6.9. The $\mathrm{pH}$ value was in the acidic range, indicating compatibility after its application on the skin.

Table 2 Evaluation of production yield, drug content, and loading efficiency

\begin{tabular}{|l|l|l|l|}
\hline $\begin{array}{l}\text { Formulation } \\
\text { code }\end{array}$ & $\begin{array}{l}\text { Practical } \\
\text { yield }(\mathrm{mg})\end{array}$ & $\begin{array}{l}\text { Production } \\
\text { yield (\%) }\end{array}$ & $\begin{array}{l}\text { Loading/ } \\
\text { encapsulation } \\
\text { efficiency (\%) }\end{array}$ \\
\hline M1 & 112 & $37.33 \pm 1.3$ & $35.83 \pm 1.8$ \\
\hline M2 & 212 & $53 \pm 2.1$ & $46.21 \pm 1.3$ \\
\hline M3 & 180 & $36 \pm 1.7$ & $57.09 \pm 2.5$ \\
\hline M4 & 202 & $50.5 \pm 1.9$ & $48.86 \pm 2.8$ \\
\hline M5 & 396 & $79.2 \pm 2.5$ & $59.86 \pm 1.6$ \\
\hline M6 & 339 & $56.5 \pm 2.6$ & $72.48 \pm 1.1$ \\
\hline M7 & 525 & $61.76 \pm 1.1$ & $84.78 \pm 1.3$ \\
\hline M8 & 756 & $84 \pm 1.6$ & $95.41 \pm 1.9$ \\
\hline M9 & 720 & $75.78 \pm 1.2$ & $97.82 \pm 2.1$ \\
\hline
\end{tabular}

Note: All values are expressed as mean \pm standard deviation $(n=3)$. 


\section{FTIR Spectral Analysis}

The FTIR spectra of the pure PTX drug and PTX-loaded microsponge (M8 formulation) were recorded by FTIR with attenuated total reflection (JASCO TTFR 4600, MESCOP, Sonai). Our data suggested that all the characteristic peaks of PTX were presented in the spectrum of the drug and prepared PTX microsponges, indicating good compatibility between the drug and the polymer. Besides, there is also no significant change in the chemical integrity of the drug. There is no change in functional group peaks of PTX in the IR spectra. FT-IR spectral results can be seen in supporting information (- Figs. S1-2 [online only]).

\section{Scanning Electron Microscopy}

SEM study showed that the porous nature of the microsponge was characterized by rough surface with typical large wrinkles and micropores (-Fig. 1). The microsponge was found in the spherical shape and showed a sponge-like structure where the drug was entrapped.

\section{Differential Scanning Calorimetry}

The DSC studies are routinely used to evaluate the crystalline state of the drug to illustrate a possible interaction between the drug and other excipients, and to provide information about the physical properties of the drug. The DSC thermograms of pure PTX ( - Fig. 2A) showed a sharp endothermic peak at $104.80^{\circ} \mathrm{C}$, which was its melting point. Such a sharp endothermic peak indicated that the used PTX was in a pure crystalline state. The thermogram of the M8 formulation (-Fig. 2B) showed that the microsponges were amorphous because a broad peak was observed at $85^{\circ} \mathrm{C}$, indicating a decrease in the melting point. This was an expected result because microsponges were all cross-linked polymers.

\section{In Vitro Drug Dissolution Study}

The dissolution study was performed for the selected formula M8, PTX self-made tablet, and pure drug PTX. - Fig. 3 shows that the cumulative percent of the drug release of M8 was high in the first 30 minutes (70\%). Drug release from PTX microsponges and the self-made tablet was determined by the dissolution rate of the drug, which is a function of aqueous solubility and particle size. The results clearly confirmed a $70 \%$ release of PTX from the M8 formulation within 30 minutes, while $20 \%$ release of PTX from the pure drug, and $27 \%$ release of PTX from the self-made tablet (-Fig. 3). The porous surface of the carrier particle makes it easy to penetrate the release media and bring it close to the entrapped drug molecule.

Besides, burst release was also observed, which could be due to the surface-adsorbed drug and the well-known porous nature of microsponges, with pores providing channels for drug release. Most drug molecules may reside on the surface
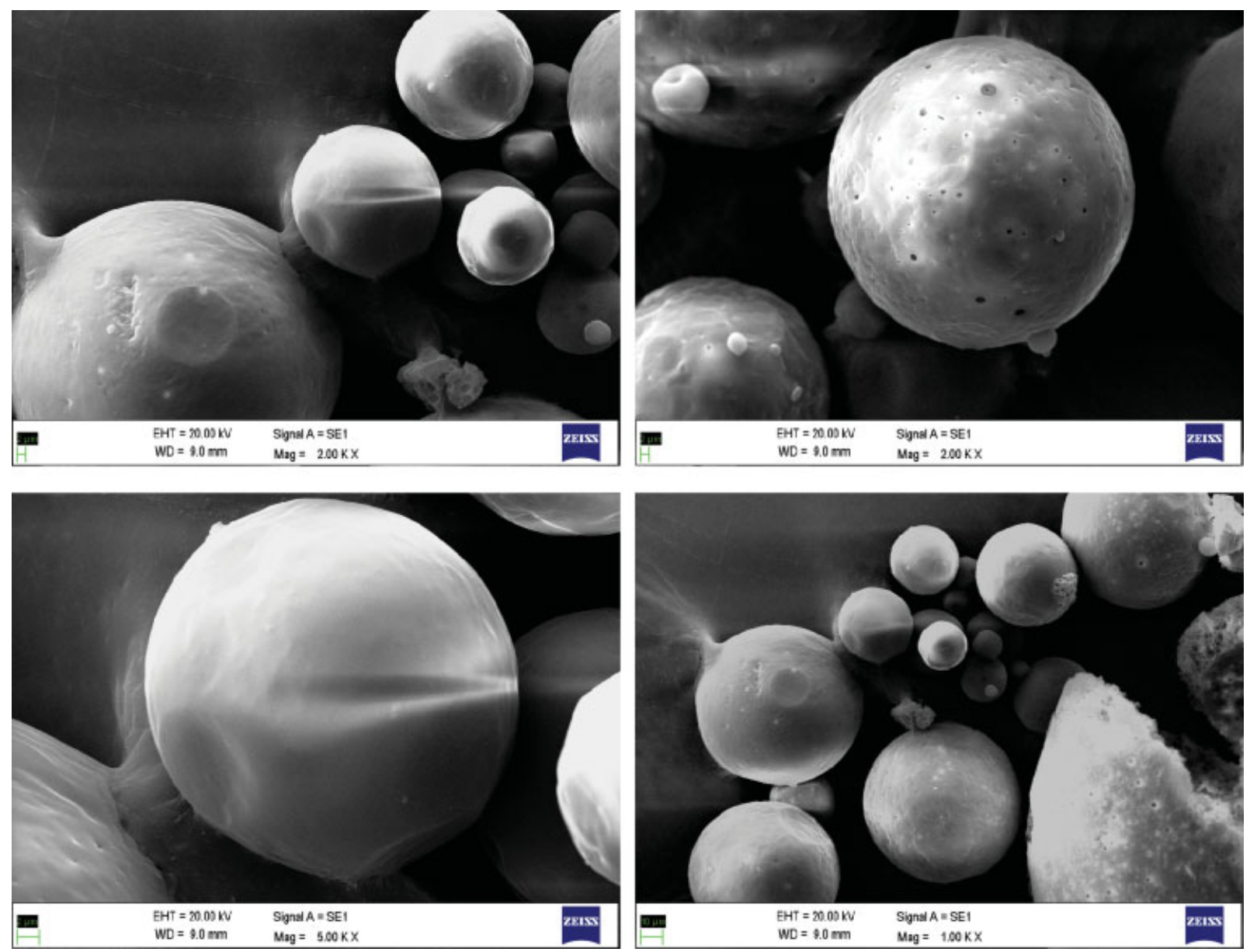

Fig. 1 SEM images of microsponges (M8). SEM, scanning electron microscopy. 

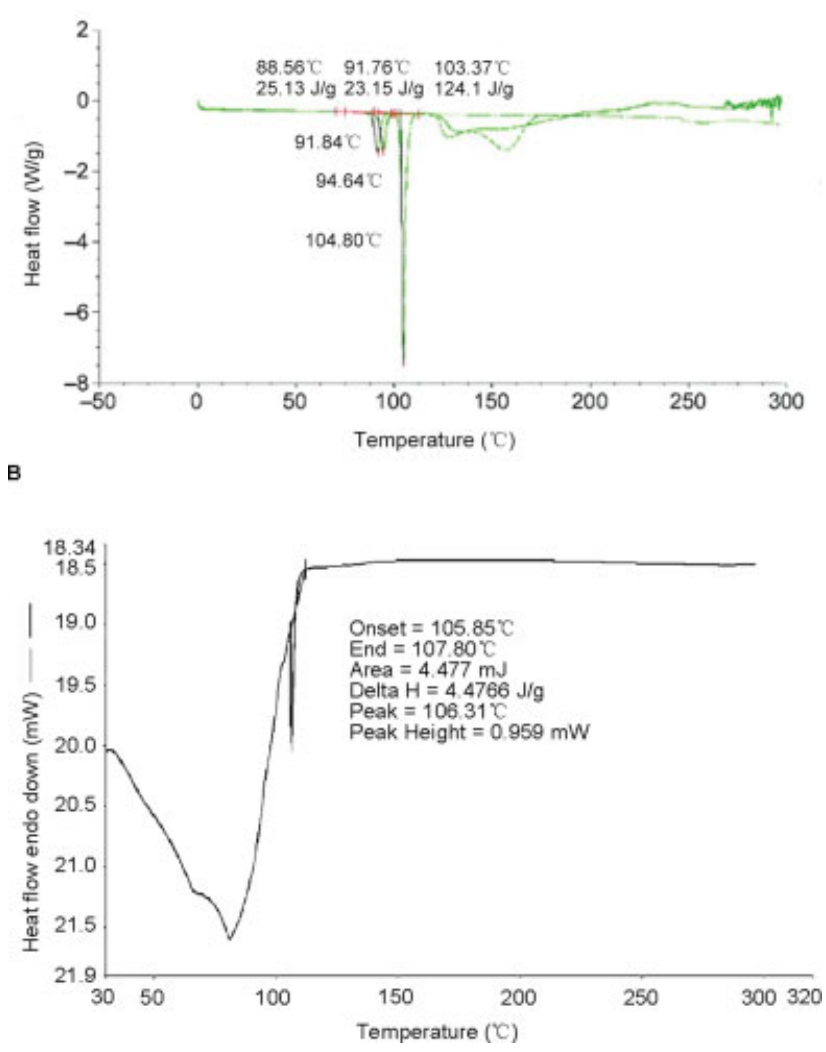

Fig. 2 DSC thermogram of (A) PTX and (B) microsponge (M8). DSC, differential scanning calorimetry. PTX, pentoxifylline.

of particulates in the form of adsorbed molecules that have the probability to rapidly dissolve, leading to quick drug release. But when the equilibrium is reached, the rate of drug release would be decreased. These results rationalized the importance of the microsponge formulation because increasing the drug surface area will lead to an increase in the dissolution rate.

The use of microsponges for oral route, where bioavailability is a major constraint, was further explored. Evidence suggested that the standard oral bioavailability of PTX is only 20 to $30 \%{ }^{15}$ The basic mechanism by which microsponges release drugs through the skin is diffusion or concentration gradient. Bioadhesion will increase the residential time of the dosage form on the site of application/action. Thus, the use of microsponge in the formation of oral tablets and transdermal patches in pipelines needs to be further studied.

\section{Effect of Porosity and Sphere Surface Area on Drug Release}

The higher the concentration of DCM, the more spongy and porous the microsponge was. The increased amount of DCM

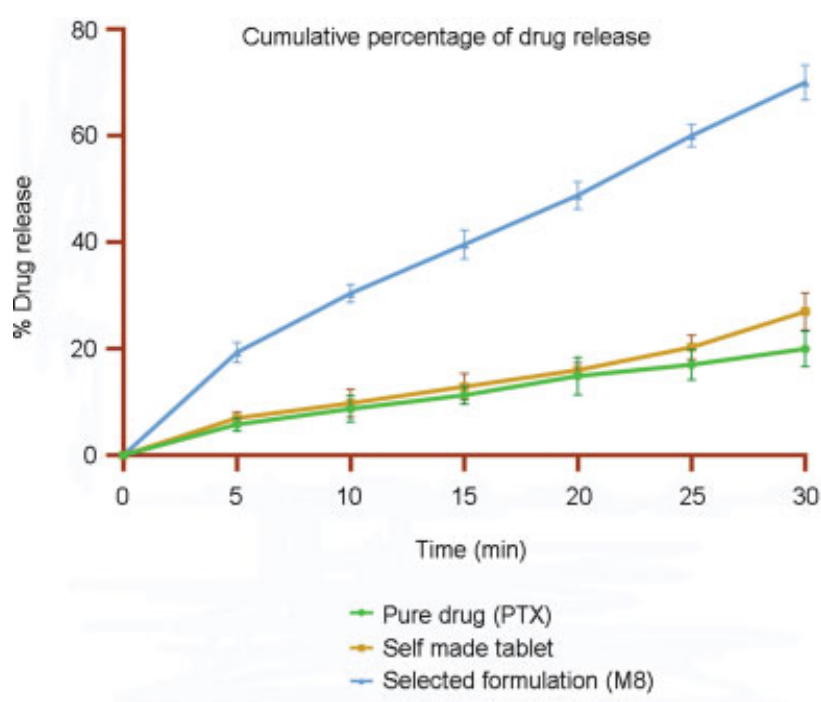

Fig. 3 Percent drug release of microsponges (M8), pure drug PTX, and self-made tablet. PTX, pentoxifylline.

causes the precipitation of the drug at the periphery of the microsponge, resulting in an increase in drug release. The increase in porosity and sphere surface area enhances the release rate of the drug delivery system.

\section{In Vivo Bioavailability Study (Pharmacokinetic Parameter)}

HPLC parameters of the pure PTX and selected M8 formulation are depicted in -Table 3. Our results showed that the retention times of pure PTX and M8 were 3.101 and 3.213 with peak areas of 21,212 and 29,528, respectively. The symmetry factor for pure PTX and M8 was below 2 as per ICH (International Council on Harmonization) guidelines. Low NTP (number of theoretical plates) indicated the column performance.

The PTX concentrations in plasma were further determined using the UV-HPLC method. The assay was sensitive, rapid, and easy to be applied to study the pharmacokinetics of PTX. The mean plasma concentration versus time profiles for PTX after a single oral dose of PTX is shown in - Fig. 4. Our data suggested that the plasma concentration of the drug in M8 formulation was increased $(9,219 \mathrm{ng} / \mathrm{mL}$ in 12 hours $)$ in comparison to pure drug PTX $(2,476 \mathrm{ng} / \mathrm{mL}$ in 12 hours $)$ (-Table 4).

Moreover, the pharmacokinetic parameters were further calculated using a noncompartmental analysis method, using WinNonlin. They are summarized in - Table 5. The plasma profile of PTX rose rapidly with $t_{\max }$ occurring at

Table 3 HPLC parameters of pure PTX and selected formulation (M8)

\begin{tabular}{|l|l|l|l|l|l|l|}
\hline & Sr. No. & Retention time & Peak area $(\mu \mathrm{V} / \mathbf{s})$ & $\%$ area & Symmetry factor & NTP \\
\hline Pure PTX & 1 & 3.101 & 21,212 & 100 & 1.536 & 127 \\
\hline M8 & 1 & 3.213 & 29,528 & 100 & 1.624 & 130 \\
\hline
\end{tabular}

Abbreviations: HPLC, high-performance liquid chromatography; NTP, number of theoretical plates; PTX, pentoxifylline. 


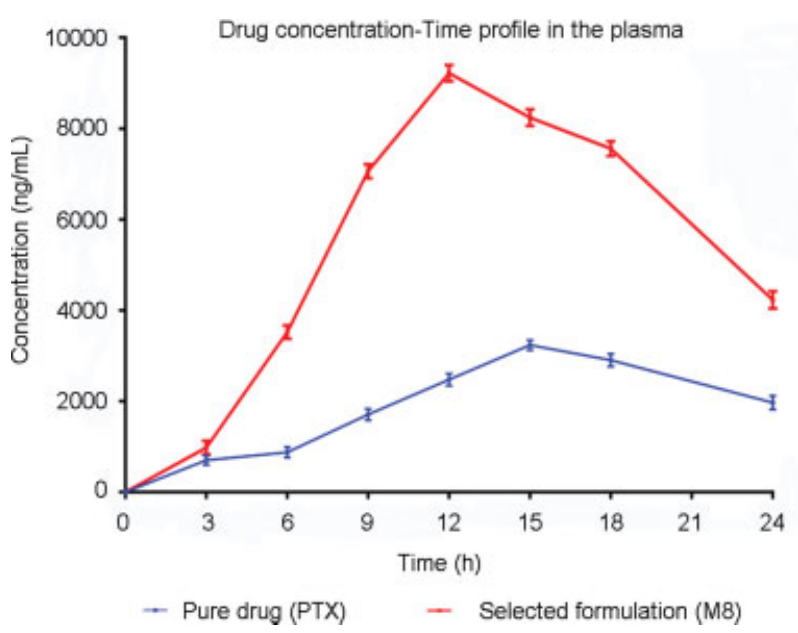

Fig. 4 Plasma concentration-time profile of pure drug (PTX) and selected formulation (M8). PTX, pentoxifylline.

Table 4 In vivo bioavailability study data

\begin{tabular}{|l|l|l|l|}
\hline $\begin{array}{l}\text { Sr. } \\
\text { No. }\end{array}$ & $\begin{array}{l}\text { Time } \\
\text { interval } \\
\text { (h) }\end{array}$ & Std. PTX & $\begin{array}{l}\text { Selected formulation } \\
\text { (M8) }\end{array}$ \\
\cline { 3 - 4 } & $\begin{array}{l}\text { Concentration } \\
\text { (ng/mL) }\end{array}$ & $\begin{array}{l}\text { Concentration } \\
\text { (ng/mL) }\end{array}$ \\
\hline 1 & 3 & $704 \pm 103.65$ & $980 \pm 152.6$ \\
\hline 2 & 6 & $875 \pm 118.2$ & $3,520 \pm 149.6$ \\
\hline 3 & 9 & $1,710 \pm 127.63$ & $7,060 \pm 156.78$ \\
\hline 4 & 12 & $2,476 \pm 135.69$ & $9,219 \pm 177.23$ \\
\hline 5 & 15 & $3,238 \pm 112.66$ & $8,240 \pm 181.2$ \\
\hline 6 & 18 & $2,902 \pm 141.3$ & $7,561 \pm 163.82$ \\
\hline 7 & 24 & $1,970 \pm 149.39$ & $4,231 \pm 191.3$ \\
\hline
\end{tabular}

Abbreviation: PTX, pentoxifylline.

Note: All values are expressed as mean \pm standard deviation $(n=6)$.

0.846 hour after oral administration of M8 when compared with the pure drug (2.32 hours). Moreover, the $C_{\max }$ value of M8 $(1,310 \mathrm{ng} / \mathrm{mL})$ was almost 16 -fold higher than that of pure PTX drug $(80.3 \mathrm{ng} / \mathrm{mL})$. The $\mathrm{AUC}_{0-\infty}$ value in plasma was 1,820 and $1,310 \mathrm{ng} / \mathrm{mL} \times \mathrm{h}$. The elimination of PTX was relatively fast in M8 with a $t_{1 / 2}$ being 1.82 in comparison to that of the pure drug PTX (1.97 hours). No significant change in $t_{1 / 2}$ was found, as would be expected from a linearly acting drug like PTX. All the above data suggested that M8 prolonged plasma levels of PTX without extending the half-life of the drug. The PTX was rapidly cleared from plasma; it underwent extensive first pass metabolism. ${ }^{16,17}$ The oral bioavailability of PTX tablet was 20 to $30 \% .{ }^{18}$ Interestingly, our in vivo study showed that the mean bioavailability of PTX from M8 was not similar to that of the pure drug (PTX). The $C_{\max }$ from the plasma profiles of the pure drug (PTX) was much lower than that of M8. According to our results, Eudragit apparently played an important role for enhancing the bioavailability of PTX. When the plasma concentrations were considered after administration, higher levels were observed with M8 than the pure drug (PTX).
Table 5 Comparative study of the pharmacokinetic parameters of selected formulation (M8) and pure drug PTX

\begin{tabular}{|l|l|l|}
\hline Parameters & $\begin{array}{l}\text { Selected } \\
\text { formulation (M8) }\end{array}$ & $\begin{array}{l}\text { Pure drug } \\
\text { (PTX) }\end{array}$ \\
\hline$t_{\max }(\mathrm{h})$ & $0.846 \pm 0.036$ & $2.320 \pm 1.289$ \\
\hline$C_{\max }(\mathrm{ng} / \mathrm{mL})$ & $1310 \pm 0.087$ & $80.3 \pm 0.329$ \\
\hline$t_{1 / 2}(\mathrm{~h})$ & $1.82 \pm 2.041$ & $1.97 \pm 1.154$ \\
\hline $\mathrm{AUC}_{(0-\mathrm{t})}(\mathrm{ng} / \mathrm{mL} \times \mathrm{h})$ & $1710 \pm 3.514$ & $542 \pm 3.419$ \\
\hline $\mathrm{AUC}_{(0-\infty)}(\mathrm{ng} / \mathrm{mL} \times \mathrm{h})$ & $1,820 \pm 3.236$ & $1,310 \pm 3.512$ \\
\hline
\end{tabular}

Abbreviation: PTX, pentoxifylline.

Note: All values are expressed as mean \pm standard deviation $(n=6)$.

PTX is hepatically metabolized by hydroxylation and demethylation into six renally excreted metabolites. ${ }^{17}$ The presence of high levels of the test PTX formulation may alter the mechanism of metabolizing enzymes by saturation, leading to the increased bioavailability of the drug. Besides, PTX is reduced extrahepatically to form an intermediate metabolite, known as hydroxyl PTX, which can be converted back to the parent compound or further metabolized..$^{19}$ PTX has a wider therapeutic range $(1,200-2,000 \mathrm{mg} / \mathrm{d})$ in humans for oral application ${ }^{20}$ and its oral bioavailability can be enhanced by Eudragit. Besides, PTX may be well tolerated when it was administered as a PTX-Eudragit formulation.

\section{Conclusion}

In this study, microsponges containing PTX were prepared successfully by a quasi-emulsion solvent diffusion method. The solubility of the drug was increased by fourfold in PTX microsponges in comparison to pure PTX. Our data suggested that the PTX:Eudragit ratio of 1:8 is suitable for the preparation of PTX microsponges with higher production yield and loading efficiency. PTX microsponges successfully enhanced aqueous solubility, dissolution profile, and oral bioavailability of the drug, and may represent a promising alternative strategy in drug therapy.

Conflicts of Interest

The authors declared that there are no conflicts of interest.

\section{Acknowledgments}

The authors are thankful to MES's College of Pharmacy, Sonai for providing all necessary facilities. Shreya Life Science, Aurangabad is gratefully acknowledged for providing PTX as a gift sample.

\section{References}

1 Bano N, Ray S, Shukla T, et al. Multifunctional nanosponges for the treatment of various diseases: a review. Asian J Pharm Pharmacol 2019;5(02):235-248

2 Krabicová I, Appleton SL, Tannous M, et al. History of cyclodextrin nanosponges. Polymers (Basel) 2020;12(05):1122 
3 Sherje AP, Dravyakar BR, Kadam D, Jadhav M. Cyclodextrin-based nanosponges: a critical review. CarbohydrPolym 2017;173:37-49

4 Chadawar V, Shaji J. Microsponge delivery system. Curr Drug Deliv 2007;4(02):123-129

5 Solunke RS, Borge UR, Murthy K, Deshmukh MT, Shete RV. Formulation and evaluation of Gliclazide nanosponges. Int J Applied Pharmaceutics 2019;11(06):181-189

6 Rajalakshmi R, Venkataramudu T, Kumar RA, et al. Dedign and characterization of valsartan nanosuspension. Int J Pharmacotherapy 2012;2(02):70-81

7 Gulati N, Tomar N, Nagaich U. MiconazoleMicrosponges based topical delivery system for diaper dermatitis. ArsPharmaceutica (Internet) 2016;57(02):77-87

8 NaikBukke SP, Nettekallu Y, Purushothama RK. Formulation and characterization of micro sponge loaded topical gel preparation of metronidazole. J Glob Trends Pharm Sci 2017;8(04):4712-4717

9 Bagde SA, Jadhav NC, Karpe MS, Kadam VJ. Formulation and evaluation of topical microsponge based gel of bifonazole. Indo Am J Pharmaceutical Res 2016;6(04):5307-5319

10 Jadha V N, Patel V, Mungekar S, Bhamare G, Karpe M, Kadam V. Microsponge delivery system: an updated review, current status and future prospects. Int J Applied Pharm 2013;2(06):1097-1110

11 Yadav V, Jadhav P, Dombe S, Bodhe A, Salunkhe P. Formulation and evaluation of microsponge gel for topical delivery of antifungal drug. Int J Applied Pharm 2017;9(04):30-37
12 Hussain H, Dhyani A, Juyal D, Bahuguna A. Formulation and evaluation of gel-loaded microsponges of diclofenac sodium for topical delivery. PharmaInnov 2014;3(10):58-63

13 Osmani RA, Aloorkar NH, Ingale DJ, et al. Microsponges based novel drug delivery system for augmented arthritis therapy. Saudi Pharm J 2015;23(05):562-572

14 Indora N, Kaushik D. Design, development and evaluation of ethosomal gel of fluconazole for topical fungal infection. Int J EngSci Invention Res Dev 2015;1(08):280-306

15 Rojanasthein N, Kumsorn B, Yuen K. Bioequivalence study of generic Pentoxifylline. Chiang Mai Med Bull 2003;42(01):7-16

16 Hinze HJ, Grigoleit HG, Rethy B. Bioavailability and pharmacokinetics of Pentoxifylline from "Trental 400" in man. Pharmatherapeutica 1976;1(03):160-171

17 Smith RV, Waller ES, Doluisio JT, et al. Pharmacokinetics of orally administered pentoxifylline in humans. J Pharm Sci 1986;75(01): 47-52

18 Beermann $\mathrm{B}$, Ings R, Månsby J, Chamberlain J, McDonald A. Kinetics of intravenous and oral pentoxifylline in healthy subjects. ClinPharmacolTher 1985;37(01):25-28

19 Mauro VF, Mauro LS, Hageman JH. Alteration of pentoxifylline pharmacokinetics by cimetidine. J ClinPharmacol 1988;28(07):649-654

20 Antignani PL, Todini AR, Saliceti F, Pacino G, Bartolo M. Results of clinical, laboratory and haemorheological investigations of the use of pentoxifylline in high doses. Pharmatherapeutica 1987;5(01):50-56 